\title{
Building Technology-Based Training on Relevant Learning Perspectives
}

\author{
Timo Lainema \\ Turku School of Economics and Business Administration
}

\begin{abstract}
Today, much of the work within technology-based learning use constructivism as a reference 'discipline' but few of the work done within the field discusses thoroughly, what are the basic assumptions and implications of constructivism. As a result, the technology has driven the applications, with theory only vaguely or superficially applied. Constructivism provides one theoretical approach to the use of computer-based learning systems. In this paper we discuss how constructivism adds value on technology-based learning discussion. Going through these different views will introduce how our understanding of technology based learning and the role of the learner in this process has changed during the last two decades.
\end{abstract}

Key words: Collaborative Learning, Learner Centered Learning, Teaching Methods.

\section{INTRODUCTION}

Jonassen and Land (2000) note that during the 1990's we have witnessed a convergence of learning theories never before encountered. These contemporary learning theories are based on substantially different ontologies and epistemologies than what used to be the traditional objectivist foundations for instructional design. However, much of the discussion on higher education has been about markets and applications, and very little is said about learning. We are interested in constructivism because it seems to give a lot of suggestions about how to construct computer-based (e-learning) environments.

Constructivism is a view of learning that emerges from the discipline of Education. It is a set of principles that can be applied also when designing 
computer-based instructions. Principles often mentioned in relation to constructivism are, for example: all learning is a process of construction; knowledge is context dependent and learning should occur in contexts to which it is relevant; learning is an inherently social-dialogical activity grounded in talk; learners are participants in a sociocultural process.

Bednar et al. (1992) argue that in the field of instructional systems technology it has been appropriate to select principles and techniques from many theoretical perspectives, choosing those we like best and ending up with a design technology based on no single theoretical base. Thus, concepts and strategies are abstracted out of their theoretical framework. However, effective instructional design emerges from the deliberate application of some particular theory of learning.

Before introducing constructivism, we briefly discuss experiential learning. Experiential learning theory is one of the most influential theories of management learning. Experientialism and constructivism have a lot in common. Just to mention one similarity, these views refer to Dewey, Piaget, and Lewin as their original authors. We see these views of learning as supporting and supplementing each other. Together they give us an enlarged understanding of learning through experimentation and on the basis of that give us more capabilities to study and analyze learning.

\section{EXPERIENTIAL LEARNING}

Experiential learning theory points to the significance of learning through direct experience as opposed to learning through 'instruction'. The learners act as decision-makers and see the consequences of their decisions. An important aspect of this view is that learning occurs through the resolution of conflicts. However, in the real world, learning from experience is not that self-evident. Actions taken in one area may have significant effects in distant parts of the system, but these effects may be obscure to the original actors. Thus, decision-makers cannot see the consequences of their decisions. This supports the use of learning environments that represent causal relationships and where time is accelerated: the link between a decision and its outcomes becomes explicit.

Kolb (1984) notes two aspects of the experiential learning model. The first one is the emphasis on here-and-now concrete experience to validate and test abstract concepts. Immediate personal experience is the focal point for learning. This experience gives life, texture, and subjective personal meaning to abstract concepts and at the same time provides a concrete, publicly shared reference point for testing the implications and validity of ideas created during the learning process. The second aspect that Kolb 
emphasizes in this learning model is that training is based on feedback processes. The information feedback provides the basis for a continuous process of goal-directed action and the evaluation of the consequences of that action. Argyris and Schön (1978) have described a model where the process moves from discovery of problems, to invention of solutions, to production of solutions in action, to reflection on the impact of these actions, and then back to discovery (Figure 1).

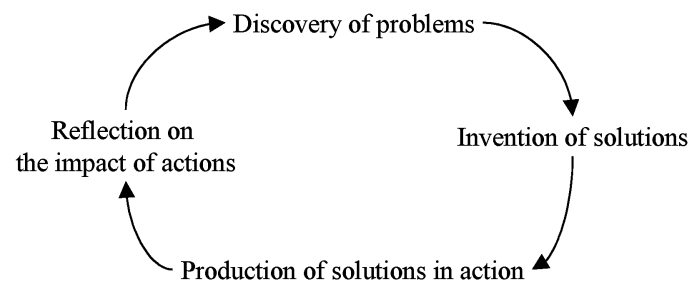

Figure 1. Learning cycle by Argyris and Schön (1978).

But this ideal learning cycle fails to operate effectively in organizations because of limits at each of the points in the cycle that are connected to everyday work activities and decision-making processes (Isaacs and Senge, 1992). These limits may cause, for example, the delays between when decisions are made and their impact to be very long. In general, these delays make it more difficult for the decision-makers to see the outcomes of their decisions.

Experiential learning environments receive support also from the field of organizational learning (OL). Some central concepts in OL are single- and double-loop learning (Argyris and Schön, 1996), which explain why it is often so difficult to achieve real change in individuals. Single-loop learning (SLL) is instrumental learning that changes strategies of action or assumptions underlying strategies in ways that leave the values of a theory of action unchanged. Double-loop learning (DLL) results in a change in the values of theory-in-use, as well as in its strategies and assumptions. SLL is sufficient when error correction can proceed by changing strategies and assumptions within a constant framework of values and norms. It is instrumental and concerned primarily with effectiveness. In some cases, however, the correction of error requires inquiry through which organizational values and norms themselves are modified.

Villegas (1997) describes the process of experimenting with a computerbased learning environment (CBLE) as follows (Figure 2). The participants might experience 'aha effects' which are indicators that they have found 
something unexpected in the CBLE. To correct this discrepancy the participants use their present mental model (SLL). During the process of trial and error the participants may notice that the discrepancies cannot be explained with their existing mental models. They may reach a better understanding of the problems exhibited in the CBLE and consequently a better insight into the real-world system (thus, modify their mental model to better represent the actual nature of the real-world system). If they change the way they explain a certain situation or realize how the real system works, they have improved their mental models and DDL has taken place.

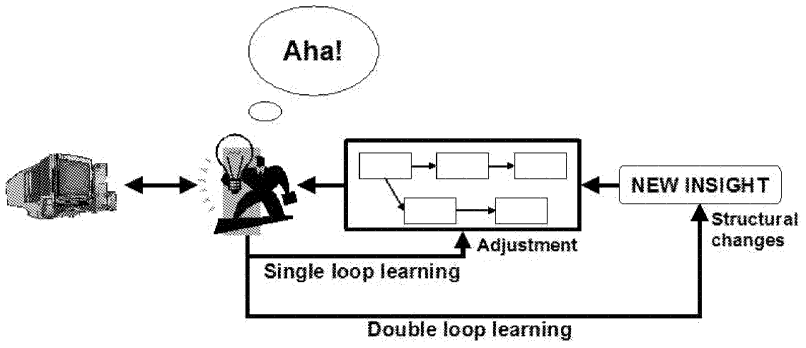

Figure 2. Individual single and double loop learning based on experimentation with a learning environment (Villegas, 1997).

As a CBLE is placed to the learning cycle introduced in Figure 1 the result is the cycle in Figure 3. Here Isaacs and Senge (1992) use the term 'virtual world' by Argyris and Schön instead of CBLE. This figure illustrates how a CBLE can turn visible the learning limits that are obscure in real world. CBLEs provide a rapid, unambiguous, and systemic feedback on actions taken. They provide a relatively low-risk setting in which differences in mental models can be explored. CBLEs can reflect back previously tacit assumptions and can provide insights into the nature of the complex interactions that determine the consequences of decisions. 


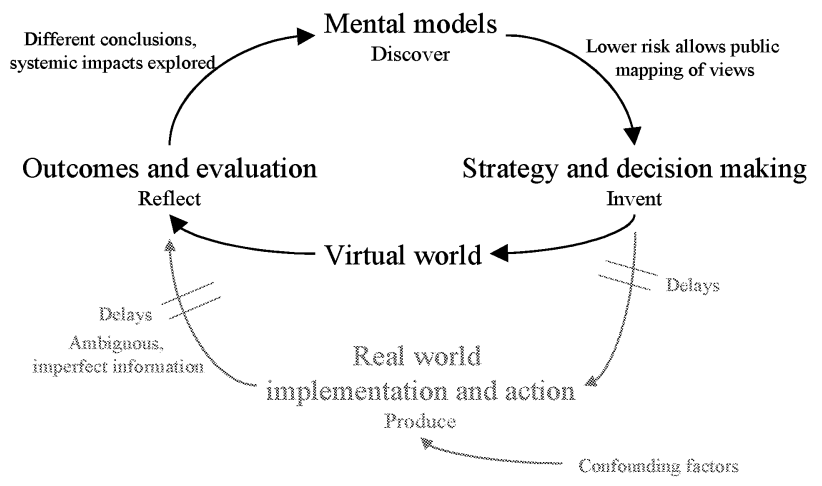

Figure 3. The impact on learning using virtual world (Isaacs and Senge, 1992).

\section{CONSTRUCTIVISM}

Also constructivism supports experience as a source of learning and team-based learning, but it further expands and explains the characteristics of successful technology-based learning environments. To our mind constructivism is not in conflict with experiential learning. Constructivism more like complements the available toolkit of explaining how to create successful learning environments. As noted, experience has a central position in the constructivist view.

Today's ways of understanding learning can be appreciated only against the historical background of thoughts on human learning and in relation to one another. All the theories still remain a vital part of the way we think. Unlike many other scientific theories, learning theories are generally not replaced by superior ones, but rather incorporated into subsequent theories. The most influential theories have been behaviourism and cognitive psychology (Lehtinen \& Kuusinen, 2001).

One way of looking at different views on learning is described by Duffy and Jonassen (1992). The objectivist tradition acknowledges that people have different understandings based on differing experiences. However, the impact of prior experience and human interpretation is seen as leading to partial understandings and biased understandings. The goal here is to strive for the complete and correct understanding. Knowledge is believed to exist independently of instruction and there is no need to look at the instructional activities to see what is learned. The objectivist epistemology underlies Behaviourism and much of cognitive psychology. Another way of thinking about learning is constructivism, which we will describe in the following. 
Bednar et al. (1992) state that the aim of using learning environments should be to facilitate situating cognition in real-world contexts, teaching through cognitive apprenticeship, and construction of multiple perspectives. By real-world contexts Bednar et al. mean that the task is not isolated but rather a part of a larger context. We should create environments that capture a larger context in which the problems are relevant. Also the reason for solving the problems must be authentic to the context in which the learning is to be applied. The environmental context is critical. The learning context forms an inexorable link with the knowledge embedded within it. Thus, an abstract, simplified environment is not just quantitatively different from the real-world environment but it is also qualitatively different. Authentic learning environments may be expected to vary in complexity with the expertise of the learner.

The authenticity argument receives support from Spiro et al. (1991). A common thread running through the deficiencies in learning is oversimplification. Compartmentalization of knowledge components works as an effective strategy in well-structured domains, but blocks effective learning in more intertwined, ill-structured domains that require high degrees of knowledge interconnectedness. Ill-structured domains require multiple representations for full coverage. Spiro et al. found that a single analogy may help at early stages of learning, but actually interferes with more advanced treatments of the same concept, when the knowledge domain is more intertwined and ill-structured requiring high degrees of knowledge interconnectedness.

Spiro et al. (1991) argue that revisiting the same material, at different times, in rearranged contexts, for different purposes and from different conceptual perspectives is essential for attaining the goals of advanced knowledge acquisition. Content must be covered more than once for full understanding because of psychological demands resulting from the complexity of case in ill-structured domains. Re-examining a case in the context of comparison with a case different from the comparison context will lead to new insights.

Duffy and Cunningham (1996) present and justify their version of Constructivism in a paper often referred to in the field of education:

- All knowledge is constructed; all learning is a process of construction. Learning is a matter of changes in one's relation to the culture to which one is connected.

- Many world views can be constructed; hence there will be multiple perspectives. The engagement with others creates the awareness of multiple perspectives.

- Knowledge is context dependent, so learning should occur in contexts to which it is relevant. 
- Learning is mediated by tools and signs. All distinctly human instances of learning are constructions situated within a context that employs some form of mediational means, tools, and/or signs.

- Learning is an inherently social-dialogical activity. Knowledge, and thereby learning, is a social, communicative, and discursive process, inexorably grounded in talk.

- Learners are distributed, multidimensional participants in a sociocultural process. A distributed concept of self shifts the activity of learning to the connections one has with communities, to the patterns of participation, and away from efficient internalization of knowledge.

- We are generally unaware of the beliefs we have adopted or created to live and teach by; raising them to awareness can have salutary effects.

Duffy and Cunningham (1996) describe problem-based learning, which they feel exemplifies the constructivist theory. The focus should be on developing the skills related to solving the problem as well as other problems like it. Skills are developed through working on the problem, i.e. through authentic activity. It is impossible to describe what is learned in terms of the activity alone or in terms of the content alone, rather, it is the activity in relation to the content that defines learning. The teacher does not teach students what they should do/know and when they should do/know it. Rather, the teacher supports the students in developing their critical thinking skills, self-directed learning skills, and content knowledge in relation to the problem.

\section{CONCLUSIONS}

Today, the basic principles of Constructivism seem to be more or less established: Technologies can support learning if they are used as tools that help learners to think. However, effective technology-based learning environments are hard to find. According to constructivism we should create projects or environments that capture a larger context in which the problems are relevant. So, what are constructivist learning environments (CLEs)?

Jonassen et al. (1999) find this question to be a difficult one to answer. They state that CLEs are technology-based environments, in which students explore, experiment, construct, converse, and reflect on what they are doing, so that they learn from their experiences. Learners are presented with a complex and relevant problem, project, or experience that they accept or reject as a challenge. Then the CLE provides them with the tools and resources that they need to understand the problem and to solve it (or attempt to solve it). Jonassen et al. describe the components needed in successful CLEs: 
- Problem/project space: learners are presented with an interesting, relevant, and engaging problem to solve. The problem should be complex and somewhat ill-defined and based on a real-world situation.

- Related cases: When expecting the learners to solve problems, it is important for the learning environment to provide access to a set of related experiences on which the learners can draw. This supports learning by representing complexity (multiple perspectives).

- Conversation (knowledge-negotiation) tools, to support collaboration.

- Social/contextual support: The weakest part of the process of instructional design has been the implementation of the technology. This is because the innovators fail to consider physical environment or social, organizational, and cultural aspects of the environment.

Constructivism is clearly a topic that needs to be studied further in the field of computer-based learning environments.

\section{REFERENCES}

Argyris, C., \& Schön, D. (1978). Organizational Learning: A Theory of Action Perspective. Massachusetts: Addison Wesley.

Argyris, C., \& Schön, D. (1996). Organizational Learning II: Theory, Method, and Practise. Massachusetts: Addison Wesley.

Bednar, A. K., et al. (1992). Theory into Practice: How Do We Link? In T. Duffy \& D. H. Jonassen (Eds.) Constructivism and the Technology of Instruction. (pp.17-34). Mahwah, NJ: Lawrence Erlbaum Associates.

Duffy, T. M., \& Cunningham, D. J. (1996). Constructivism: Implications for the Design and Delivery of Instruction. In D. H. Jonassen (Ed.) Handbook of Research for Educational Communications and Technology. (pp. 170-198). Macmillan, New York.

Isaacs, W. \& Senge, P. (1992). Overcoming limits to learning in computer-based learning environments. European Journal of Operational Research, 59, 183-196.

Jonassen, D. H. (1992). Evaluating Constructivist Learning., In T. Duffy \& D. H. Jonassen (Eds.) Constructivism and the Technology of Instruction. (pp. 137-148). Mahwah, NJ: Lawrence Erlbaum Associates.

Jonassen, D. H., \& Land, S. (2002). Preface. In D, Jonassen \& S. Land (Eds.) Theoretical Foundations of Learning Environment. Mahwah, NJ: Lawrence Erlbaum Associates.

Jonassen, D. H., Peck, K. L., \& Wilson, B. G. (1999). Learning with Technology; A Constructivist Perspective. New York: Prentice Hall.

Kolb, D. (1984). Experiential Learning: Experience the Source of Learning and Development. New York: Prentice-Hall.

Merrill, M. D. (1992). Constructivism and Instructional Design. In T. Duffy \& D. H. Jonassen (Eds.) Constructivism and the Technology of Instruction, (pp. 99-114). Mahwah, NJ: Lawrence Erlbaum Associates.

Spiro, R. J., Feltovich, P. J., Jacobson, M. J., and Coulson, R. L. (1991). Cognitive flexibility, constructivism, and hypertext. Educational Technology, (pp. 24-33). Online: http://www.ilt.columbia.edu/ilt/papers/Spiro.html 
Villegas, J. (1997). Simulation Supported Industrial Training. In Saunders and Cox (Eds.) The International Simulation and Gaming Yearbook, (Vol. 5) London: Kogan Page.

\section{BIOGRAPHY}

Timo Lainema has research interests in developing interactive and authentic business games for business education purposes. This research is multidisciplinary and includes such research topics as the impact of time in decision-making, business processes, structured vs. unstructured decision-making, experiential learning, organizational learning and constructivist learning principles. Timo's email address is timo.lainema@tukkk.fi. 